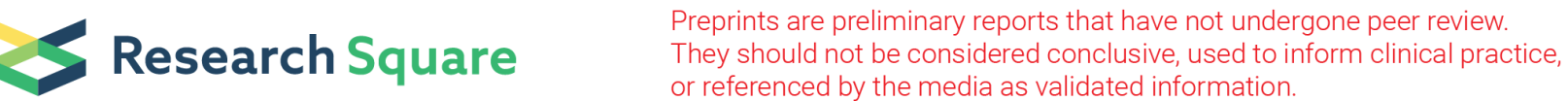

\section{Maternal emotional states in relation to their offspring weight status and health-related quality of life: Tehran Lipid and Glucose Study}

\section{Parnian Parvin}

Research Institute for Endocrine Sciences, Shahid Beheshti University of Medical Sciences

\section{Parisa Amiri ( $\sim$ Amiri@endocrine.ac.ir)}

Research Center for Social Determinants of Endocrine Health, Research Institute for Endocrine Sciences, Shahid Beheshti University of Medical Sciences https://orcid.org/0000-0002-3198-4941

\section{Sara Jalali-Farahani}

Research Institute for Endocrine Sciences, Shahid Beheshti University of Medical Sciences

\section{Mehrdad Karimi}

Research Institute for Endocrine Sciences, Shahid Beheshti University of Medical Sciences

\section{Mina MoeinEslam}

Research Institute for Endocrine Sciences

\section{Fereidoun Azizi}

Research Institute for Endocrine Sciences, Shahid Beheshti University of Medical sciences

\section{Research}

Keywords: Quality of life, Maternal mental health, Weight, Children

Posted Date: August 3rd, 2020

DOl: https://doi.org/10.21203/rs.3.rs-50159/v1

License: (c) (1) This work is licensed under a Creative Commons Attribution 4.0 International License. Read Full License 


\section{Abstract}

Background: Maternal characteristics have been known to be associated with parenting practices that could eventually influence their child's weight and health-related quality of life (HRQoL). This study aimed to assess the direct and indirect associations of maternal emotional states (depression, anxiety and stress) with body mass index (BMI) and HRQoL in their children.

Methods: This study was conducted within the framework of Tehran Lipid and Glucose Study (TLGS). Participants were children $(n=231)$ who participated in the TLGS during 2014-2016 with complete data on maternal emotional states. Body weight and height of children were measured using standard protocol and BMI-Z scores were determined using Anthroplus. HRQoL in children and emotional states in mothers were assessed using the Iranian version of the pediatric quality of life inventory (PedsQL TM 4.0) and the depression, anxiety and stress scales (DASS-21) respectively. Structural equations modeling (SEM) was used to assess the direct and indirect relations of maternal emotional states with children's BMI Z score and HRQoL.

Results: Mean age, BMI Z-score and HRQoL total score in children were $13.8 \pm 3.1$ years, $0.74 \pm 1.5$ and $84.7 \pm 11.3$ respectively. In mothers, median scores (Interquartile ranges) of DASS-21 in three scales including depression, anxiety and stress were 4(0-10), 6(2-12) and 14(8-20) respectively. Maternal level of education was significantly associated with DASS-21 scores $(\beta=-0.23,95 \% \mathrm{Cl}$ : $-0.37,-0.07)$. Maternal DASS-21 scores were significantly associated with BMI Z scores only in girls ( $\beta=0.25,95 \% \mathrm{Cl}: 0.06,0.53)$. Significant determinants of HRQoL in boys were child's age $(\beta=-0.21,95 \% \mathrm{Cl}:-0.40,-0.01)$, maternal education ( $\beta=-0.24,95 \% \mathrm{Cl}:-0.44,-0.02)$ and emotional state $(\beta=-0.24,95 \% \mathrm{Cl}:-0.44,-0.03)$. Child's age $(\beta=-0.33,95 \%-\mathrm{Cl}:-0.53,-0.10)$ and maternal emotional state $(\beta=-0.31,95 \% \mathrm{Cl}:-0.54,-0.08)$ were significantly associated with HRQoL in girls.

Conclusion: Our results indicate maternal emotional states to be the important determinants of HRQoL in children, regardless of their weight status. Further research is recommended to examine the current hypothesized model in rural and sub-urban populations taking ino consideration more influential factors.

\section{Introduction}

Obesity is defined as accumulation of excess body fat that affects individuals' health and wellbeing [1]. According to the World Health Organization (WHO), over than $10 \%$ of the world's population is obese, with the sharp rising trend of overweight in children and adolescents indicating childhood obesity to be a global problem [2]. Based on a recent systematic review and meta-analysis conducted on 93 qualified studies, the prevalence of overweight and obesity in Iranian children and adolescents has been estimated at $12 \%$ and $7 \%$ respectively with an incidence rate of $9 \%$, according to WHO criteria [3]. Obesity is accepted as a chronic condition which may lead to several health issues including cardiovascular diseases, type 2 diabetes, stroke, asthma and may eventually end up having certain effects on both psychological and behavioral functions $[4,5]$. According to previous findings, children suffering from obesity may have 
behavioral problems, low self-esteem and depression which could adversely affect their future academic performance and health-related quality of life (HRQoL) $[6,7]$.

Health-related quality of life is defined as a comprehensive and multidimensional concept for assessment of the patient's point of view about the impact of health or disease on his/her physical, mental and social well-being and it is now considered to be an important health outcome [8]. The association between children weight status and HRQoL is controversial. While some studies emphasize the negative impact of childhood obesity on $\operatorname{HRQoL}[9,10]$, others have not shown a significant relationship between them $[11,12]$. Similar studies from Iran indicate lower HRQol scores in obese children, compared to their over- or normal-weight counterparts $[13,14]$ which can be observed in a gender-specific pattern [15]. On the other hand results of a longitudinal study conducted on European children revealed bidirectional associations between childhood overweight and psychosocial well-being [16]; findings consistent with previous data indicate that mental health problems and poor psychosocial well-being during childhood increased the risk of future obesity [17-19]. Hence, investigating the association between weight status and HRQoL in children and adolescents, considering the main factors that can affect their weight and HRQoL simultaneously, would provide much needed data on this very important relationship.

Family environment and parental characteristics are well-known determinants of both obesity and HRQoL in the early years of life $[20,21]$. Previous studies conducted in Iran have also reported the importance of various parental factors including parental age, educational level, employment, and weight status on overweight and obesity among children [22-25]. Our recent study on parental factors influencing children's weight status demonstrated the vital role of maternal socio-demographic and cardio-metabolic characteristics in distinguishing parental risk clusters as one of the main predictors of obesity in children [26]. The role of mothers in shaping children's behavioral patterns and HRQoL plays a crucial role, due to their deep emotional connections [27]. Significant contributions of maternal emotional distress in child obesity is well documented $[28,29]$. Also, There is also more evidence indicating that children's whose mothers suffer from emotional distress are much more likely to report poor HRQoL [30, 31]. Considering the evidence documented on the association of maternal negative emotional states with obesity and poor HRQoL in their children, in addition to the adverse effects of childhood obesity on HRQoL, weight status in children and adolescents could be a probable mediating factor that exacerbates the effect of maternal psychological distress on children's HRQoL indirectly. Hence, using structural equation modeling approach, the current study for the first time aimed to investigate direct and indirect effects of maternal emotional states including depression, anxiety and stress simultaneously, on children weight status and HRQoL among a population of Tehranian families.

\section{Methods}

The participants of the current study were recruited from among participants of the Tehran Lipid and Glucose Study (TLGS), a prospective research conducted to determine and modify risk factors of noncommunicable diseases. Measurements were documented at baseline (1999 - 2001) and were repeated 
every three years. Further details regarding rationale and design of the TLGS have been reported elsewhere [32, 33].

\section{Study participants}

Data for all school-aged children (aged 8 to 18 years), who participated in the TLGS during 2014-2016 were considered for the current study $(n=309)$. After excluding those with incomplete maternal information ( $n=78), 231$ individuals ( $51 \%$ boys) were recruited for the final analysis.

\section{Measurements}

Data on age and anthropometric indices, including weight and height of children were collected by trained interviewers and staff. Participant weight was measured using a digital scale while wearing minimum clothing and no shoes. Participant height was measured in a standing position with shoulders in normal alignment, and without shoes. WHO AnthroPlus (version 3.2.2) and macros software were used to determine BMI-for-age (BMI Z-score).

Health-related quality of life (HRQoL) in children was measured using the Pediatric Quality of Life Inventory ${ }^{\text {TM }}$ version 4.0 (PedsQL ${ }^{\text {TM }} 4.0$ ) Generic Core Scales which consists of 23 items and four subscales (Physical functioning, Emotional functioning, Social functioning and School functioning) [34]. For each item, children choose their answers from the five-point Likert scale ranging from 0-4 ( $0=$ never a problem to 4 = almost always a problem). To score the scale each item is reversely scored and higher scores indicate better HRQoL. Previous studies have assessed and reported the reliability and validity of the Persian version of the PedsQL ${ }^{\mathrm{TM}} 4.0$ in Iranian children (8-12 years) and adolescents (12-18 years) $[35,36]$.

In addition, in the current study maternal data including age, education, working status and emotional state were assessed. Maternal emotional state was assessed using the depression, anxiety and stress scale - 21 Items (DASS-21), which is applied for measurement of three related states of depression, anxiety and stress [37]. Each scale of DASS-21 contains seven items and each item is scored on a four point Likert scale from 0 to $3(0=$ did not apply to me at all and $3=$ applied to me very much, or most of the time). Scores for each scale are calculated by summing the scores of relevant items and a higher score in each scale of depression, anxiety and stress indicates a more severe condition on the related scale. In the current study, the Persian version of DASS- 21 was used, the validity and reliability of which have been confirmed and reported previously [38].

\section{Statistical analysis}

Data were represented as mean \pm SD for normal distributed variables and median (quartile 1, quartile 3 ) for variables with non-normal distribution. Normality assumption was examined by Shapiro-Wilk test. Chisquare test was conducted to compare categorical variables between boys and girls. Independent samples T-test or its alternative non-parametric method, Mann-Whitney $U$ test, was used for mean comparison at two groups. Structural equation modeling (SEM) was used for examining direct and indirect associations among measured variables. The Hypothesized conceptual model has been 
proposed to examine interrelationship among variables is illustrated in figure 1. Maternal education, age and employment status which describe the maternal socio-demographic status were exogenous independent variables. Maternal emotional state and children's BMI were entered in the model as mediators and children's HRQoL was considered as the final dependent variable. Maternal emotional state and children's BMI were considered as latent constructs and were measured by their special indicators. Multiple group SEM analysis was conducted for sex-specific evaluations. The Maximum likelihood method and Bayesian analysis were used for parameter estimation. Uniform distribution was set as a prior distribution of parameters and stability and admissibility criteria were examined on prior data: Mean (95\% confidence interval) of a marginal posterior distribution are reported as parameter estimates [39]. Fit indices including Chi-Square value to DF ( $\left.\chi^{2} / \mathrm{df}\right)$, Goodness of Fit (GFI), Normed Fit Index (NFI), Incremental Fit Index (IFI), Comparative Fit Index (CFI), Root Mean Square Error of Approximation (RMSEA), and Standardized Root Mean Square Residual (SRMR) were calculated to measure model adequacy and appropriateness of SEM analysis. The acceptable thresholds of fit indices have been reported by Hooper. D et al. [40]. IBM SPSS statistics23 and AMOS23 have been utilized for data description and SEM analysis respectively.

\section{Results}

Mean age, BMI Z score, $\mathrm{HRQ}$ oL total score of study participants were $13.8 \pm 3.1$ years, $0.74 \pm 1.5$ and $84.7 \pm 11.3$ respectively. Further descriptive statistics of study participants by sex groups are presented in table 1. There were no significant differences between boys and girls in mean age, BMI Z score and HRQoL scores in social functioning and school functioning; however, HRQoL scores were significantly higher in boys, compared to girls in physical and emotional functioning. Mean age of mothers was $42.2 \pm 5.8$ years, majority of whom were housewives (80.5\%) and had secondary levels of education $(57.1 \%)$. There were no significant differences between mothers of boys and girls in DASS-21 scores or distribution of maternal working status and education.

Based on multiple group analysis, the model in which the effects of maternal characteristics on maternal emotional state and measurement model of maternal emotional state have been considered the same in boys and girls were significantly better fitted on data $\left(\Delta \chi^{2}=27.65, D F=14, p=0.01\right)$, compared to the unconstrained model (in which all the parameters were considered different in boys and girls); therefore, a sex-specific analysis with some mentioned constraints was conducted.

Figure 2 displays the final structural models in boys and girls; the significant associations among variables have been drawn in figures and related standardized estimations are reported above each path;fit indices of SEM models which are reported below figure 2, indicate acceptable thresholds for both boys and girls.

Table 2, displays the examined structural model results in the sex-specific associations of maternal characteristics and children HRQoL. In the hypothesized SEM, maternal age, education and working status as well as children age were exogenous observed variables, the latent construct of maternal 
emotional state and children BMI Z score were mediators and children's HRQoL was an endogenous latent construct. The negative effect of maternal education on maternal emotional state was significant for both boys and girls $(\beta=-0.22,95 \% \mathrm{Cl}:-0.37,-0.07)$. Among the effects of maternal variables, only the positive effect of maternal emotional state on child's BMI Z score was significant in girls $(\beta=0.25,95 \% \mathrm{Cl}$ : $0.06,0.53)$. In terms of determinants of child's HRQoL, in boys, child's age ( $\beta=-0.21,95 \% \mathrm{Cl}:-0.39,-0.02)$, maternal education ( $\beta=-0.23,95 \% \mathrm{Cl}:-0.43,-0.01)$ and maternal emotional state $(\beta=-0.24,95 \% \mathrm{Cl}$ : $-0.44,-0.03)$ and in girls, child's age $(\beta=-0.33,95 \% \mathrm{Cl}:-0.53,-0.11)$ and maternal emotional state $(\beta=-0.31$, $95 \% \mathrm{Cl}:-0.53,-0.07)$ had significant negative effects on the child's HRQoL. Regarding indirect effects, there were no significant effects of maternal variables on child BMI Z score and HRQoL $(P>0.05)$.

\section{Discussion}

The current study aimed at examining a conceptual model of direct and indirect relations of maternal emotional states with BMI and HRQoL in their children. Our results indicate that while maternal emotional states could directly affect HRQoL in both genders, they were associated with weight status only in girls. Interestingly in both genders, weight status was not associated with HRQoL, which is why its mediating role in the association between maternal emotional states and offspring HRQoL was not confirmed. In addition, among maternal characteristics which have been considered as influential factors in the initial hypothesized model, level of education directly affected mothers' emotional states in both genders and HRQoL only in boys.

The current findings regarding the negative relationship between maternal emotional states and HRQol in children are consistent with data reported by previous studies [31, 41, 42]. Maternal depression and stress are accompanied by inappropriate parenting practices and reduced warmth and sensitivity in interactions with children which lead to delays in achieving developmental milestones and poor self-regulation and executive performance in children, and as a result, problems in their overall functioning $[42,43]$. In addition, anxious mothers via transference of negative emotional and thinking patterns to their children and lack of providing motivational environment in family, reduce their children's self-efficacy and success in future experiences [44].

Our results showed that maternal emotional states were associated with higher BMI levels in girls but not in boys. Several studies have reported the relationship between maternal emotional problems and child overweight [28, 30, 45]; however, only one study has explicitly investigated this relationship in a sexspecific pattern, focusing on maternal depression [46], and reported findings consistent with those of ours, which found a significant association between maternal depression and higher BMI only in girls; low levels of physical activity in girls mediated this relationship [46]. Existing literature shows that mothers with emotional problems are more likely to have unhealthy weight-related behaviors [29] and regarding same-gender role modeling, the impact of maternal lifestyle on daughters is greater than that on sons, resulting in higher levels of girl's BMI [47-49]. 
In the present study, neither in girls nor in boys, no relationship was observed between weight status and $\mathrm{HRQ}$ oL, findings that contradict our initial assumption regarding the mediating role of BMI in the association between maternal emotional states and HRQoL in their children. Data available on the relationship between weight status and HRQoL in children is controversial. Several studies showed negative associations between children's weight status and HRQoL $[9,10]$, as demonstrated by the Tsiros et al. systematic review conducted on 22 studies, revealing an inverse linear relationship between children's BMI and HRQoL for both pediatric self-reports and parent proxy-reports [50]. Further evidence indicates Iranian children with higher BMI are more likely to report poorer HRQoL [13]. However, consistent with current results, two other studies from Kuwait and Fiji found no strong association between children weight and HRQoL $[12,51]$; both reported that HRQoL scores in children with overweight/obesity did not differ significantly with corresponding values in their normal weight counterparts.

Our findings regarding the negative relationship between maternal education and HRQol in boys, but not in girls, are difficult to compare with those of other studies because there is no gender-specific study comparing this relationship; however, contrary to our results, several studies have documented the positive relationship between maternal education and children's HRQoL worldwide $[52,53]$ and in Iran [54]. It seems highly educated mothers who cannot work because of child care, have more parenting stress and experience less satisfaction with their mothering roles [55] which, considering the emerging sexuality in early adolescence and increasing complexity in opposite-sex relationships in the family, maternal stress has stronger effects on the son's functioning [56]. However, regarding the inconsistency of our findings with previous studies, more research is needed to clarify the relationship between the education of mothers and HRQoL in children. On the other hand, in our study, maternal education had a positive association with HRQoL in both genders through maternal emotional states, results consistent with those of previous studies [57-59]. Mothers with lower levels of education are more likely to suffer from depression, use negative and harsh parental practices which adversely affect children's mental wellbeing and their ability to learn $[57,59]$. Also, given that education is one of the indicators of socioeconomic status, mothers who are less educated have limited access to social support and childcare services and experience excessive parenting stress, which can impede their ability to adequately meet the needs of children [60]. Also, in this study, the HRQoL declined with increasing age of children, results consistent with existing literature [61, 62]. As age increases, around puberty, physical and hormonal changes occur that reduce psychological balance [63]. Also, because of the formation of new values and norms in adolescence, teenagers seeking their new identity, encounter social insecurities, moral contradictions and ambiguity in the future which may ultimately impair their subjective well-being [62].

This study is one of the first efforts to explore the direct and indirect effects of maternal emotional states on children's weight status and HRQoL using a structural equation modeling approach. Its findings also add important information to the literature available regarding the gender differences in the mentioned associations. However, certain limitations also need to be considered. First, the cross-sectional nature of this study did not allow us to derive causal relationships between studied variables. This study was conducted on an urban population of Tehran, which may limit the generalizability of current findings to 
rural and sub-urban populations. Finally, considering other influential factors including parents' relationship quality and children's coping strategies can provide a more accurate picture of the association between mothers' emotional states and their children's weight status and HRQoL.

In conclusion, our results highlight the impact of maternal emotional state on subjective health status of children in both genders irrespective of their BMI. Further research is definitely required to confirm our gender-specific findings.

\section{Abbreviations}

BMI: Body mass index, DASS-21: Depression, anxiety and stress scale-21 Items, HRQoL: Health-related quality of life, PedsQLTM4.0: Pediatric quality of life inventory, SEM: Structural Equation Modeling, TLGS: Tehran Lipid and Glucose Study, WHO: World Health Organization.

\section{Declarations}

\section{Ethics approval and consent to participate}

This study was approved by the research ethics committee of the Research Institute for Endocrine Sciences (RIES), Shahid Beheshti University of Medical Sciences. All participants of this study signed informed consent forms prior to data collection.

\section{Availability of data and materials}

Data would be available on the request of corresponding author based on the TLGS rules.

\section{Competing interests}

The authors declare that they have no competing interests.

\section{Authors' contributions}

PP, PA and SJF designed the study. PP, SJF and MME drafted the manuscript. MK carried out the statistical analysis and contributed to interpretation of data. FA revised the manuscript critically for important intellectual content. PA supervised and revised the manuscript. All authors read and approved the final manuscript.

\section{Acknowledgement}

We would like to express our appreciation to all participants who made this study possible. The authors wish to acknowledge Ms. Niloofar Shiva, for critical editing of English grammar and syntax of the manuscript. This study has been approved and funded by the Research Institute for Endocrine Sciences (RIES), Shahid Beheshti University of Medical Sciences. 


\section{References}

1. Halasi S, Lepeš J, Đorđić V, Stevanović D, Ihász F, Jakšić D, Živković-Vuković A, Cvetković M, Milić Z, Stajer A: Relationship between obesity and health-related quality of life in children aged 7-8 years. Health and Quality of Life Outcomes 2018, 16:149.

2. Haug E, Rasmussen M, Samdal O, lannotti R, Kelly C, Borraccino A, Vereecken C, Melkevik O, Lazzeri G, Giacchi M: Overweight in school-aged children and its relationship with demographic and lifestyle factors: results from the WHO-Collaborative Health Behaviour in School-aged Children (HBSC) study. International journal of public health 2009, 54:167-179.

3. Fakhri M, Sarokhani D, Sarokhani M, Dehkordi AH, Jouybari L: Prevalence of obesity in Iranian children: Systematic review and meta-analysis. Indian Journal of Medical Specialities 2019, 10:190.

4. Wardle J, Cooke L: The impact of obesity on psychological well-being. Best practice \& research clinical endocrinology \& metabolism 2005, 19:421-440.

5. Organization WH: Global strategy on diet, physical activity and health. 2004.

6. Akay AP, Ozturk Y, Avcil SN, Kavurma C, Tufan E: Relationships between pediatric obesity and maternal emotional states and attitudes. The International Journal of Psychiatry in Medicine 2015, 50:178-190.

7. Sahoo K, Sahoo B, Choudhury AK, Sofi NY, Kumar R, Bhadoria AS: Childhood obesity: causes and consequences. Journal of family medicine and primary care 2015, 4:187.

8. Testa MA, Simonson DC: Assessment of quality-of-life outcomes. New England journal of medicine 1996, 334:835-840.

9. Khairy SA, Eid SR, El Hadidy LM, Gebril OH, Megawer AS: The health-related quality of life in normal and obese children. Egyptian Pediatric Association Gazette 2016, 64:53-60.

10. Jalali-Farahani S, Shojaei FA, Parvin P, Amiri P: Comparison of health-related quality of life (HRQoL) among healthy, obese and chronically ill Iranian children. BMC Public Health 2018, 18:1337.

11. Liu W, Lin R, Liu W, Guo Z, Xiong L, Li B, Cheng K, Adab P, Pallan M: Relationship between weight status and health-related quality of life in Chinese primary school children in Guangzhou: a crosssectional study. Health and Quality of Life Outcomes 2016, 14:166.

12. Boodai SA, Reilly JJ: Health related quality of life of obese adolescents in Kuwait. BMC pediatrics 2013, 13:105.

13. Farajpour MK, PishgahRoodsari M, Salehiniya H, Soheilipour F: The relationship between body mass index (BMI) and quality of life in Iranian primary school students in Tehran, Iran. BioMedicine (France) 2018, 8:18-25.

14. Khodaverdi F, Bahram A, Jafarabadi MA: Quality of life, motor ability, and weight status among school-aged children of Tehran. Iranian journal of public health 2012, 41:97. 
15. Jalali-Farahani S, Alamdari S, Karimi M, Amiri P: Is overweight associated with health-related quality of life (HRQoL) among Tehranian school children? SpringerPlus 2016, 5:313.

16. Hunsberger M, Lehtinen-Jacks S, Mehlig K, Gwozdz W, Russo P, Michels N, Bammann K, Pigeot I, Fernández-Alvira JM, Thumann BF: Bidirectional associations between psychosocial well-being and body mass index in European children: Iongitudinal findings from the IDEFICS study. BMC Public Health 2016, 16:949.

17. Puder J, Munsch S: Psychological correlates of childhood obesity. International journal of obesity 2010, 34:S37-S43.

18. Halfon N, Larson K, Slusser W: Associations between obesity and comorbid mental health, developmental, and physical health conditions in a nationally representative sample of US children aged 10 to 17. Academic pediatrics 2013, 13:6-13.

19. Luppino FS, de Wit LM, Bouvy PF, Stijnen T, Cuijpers P, Penninx BW, Zitman FG: Overweight, obesity, and depression: a systematic review and meta-analysis of longitudinal studies. Archives of general psychiatry 2010, 67:220-229.

20. Gray LA, Alava MH, Kelly MP, Campbell MJ: Family lifestyle dynamics and childhood obesity: evidence from the millennium cohort study. BMC Public Health 2018, 18:500.

21. Huang $H$, Radzi WM, Salarzadeh Jenatabadi H: Family environment and childhood obesity: a new framework with structural equation modeling. International journal of environmental research and public health 2017, 14:181.

22. Maddah M, Nikooyeh B: Factors associated with overweight in children in Rasht, Iran: gender, maternal education, skipping breakfast and parental obesity. Public health nutrition 2010, 13:196200.

23. Hajian-Tilaki K, Heidari B: Childhood obesity, overweight, socio-demographic and life style determinants among preschool children in Babol, northern Iran. Iranian journal of public health 2013, 42:1283.

24. Doustmohammadian A, Abdollahi M, Bondarianzadeh D, Houshiarrad A, Abtahi M: Parental determinants of overweight and obesity in Iranian adolescents: a national study. Iranian journal of pediatrics 2012, 22:35.

25. Doustmohammadian A, Dorostymotlagh A, Keshavarz A, Sadrzadehyeganeh H, MohammadpourAhrangani B: Socio-demographic Factors Associated with Body Mass Index of Female Adolescent Students in Semnan City, Iran. Malaysian journal of nutrition 2009, 15.

26. Jalali-Farahani S, Amiri P, Abbasi B, Karimi M, Cheraghi L, Daneshpour MS, Azizi F: Maternal characteristics and incidence of overweight/obesity in children: a 13-year follow-up study in an eastern Mediterranean population. Maternal and child health journal 2017, 21:1211-1220.

27. Barroso CS, Roncancio A, Hinojosa MB, Reifsnider E: The association between early childhood overweight and maternal factors. Childhood Obesity 2012, 8:449-454.

28. Tate EB, Wood W, Liao Y, Dunton GF: Do stressed mothers have heavier children? A meta-analysis on the relationship between maternal stress and child body mass index. Obesity reviews 2015, 16:351- 
361.

29. O'Connor SG, Maher JP, Belcher BR, Leventhal AM, Margolin G, Shonkoff ET, Dunton GF: Associations of maternal stress with children's weight-related behaviours: a systematic literature review. Obesity reviews 2017, 18:514-525.

30. Lampard AM, Franckle RL, Davison KK: Maternal depression and childhood obesity: a systematic review. Preventive medicine 2014, 59:60-67.

31. Dittrich K, Fuchs A, Bermpohl F, Meyer J, Führer D, Reichl C, Reck C, Kluczniok D, Kaess M, Attar CH: Effects of maternal history of depression and early life maltreatment on children's health-related quality of life. Journal of affective disorders 2018, 225:280-288.

32. Azizi F, Rahmani M, Emami H, Mirmiran P, Hajipour R, Madjid M, Ghanbili J, Ghanbarian A, Mehrabi J, Saadat N: Cardiovascular risk factors in an Iranian urban population: Tehran lipid and glucose study (phase 1). Sozial-und präventivmedizin 2002, 47:408-426.

33. Azizi F, Ghanbarian A, Momenan AA, Hadaegh F, Mirmiran P, Hedayati M, Mehrabi Y, Zahedi-Asl S: Prevention of non-communicable disease in a population in nutrition transition: Tehran Lipid and Glucose Study phase Il. Trials 2009, 10:5.

34. Varni JW, Seid M, Kurtin PS: PedsQL ${ }^{m}$ 4.0: Reliability and validity of the Pediatric Quality of Life Inventory ${ }^{\mathrm{m}}$ Version 4.0 Generic Core Scales in healthy and patient populations. Medical care 2001:800-812.

35. Amiri P, Eslamian G, Mirmiran P, Shiva N, Jafarabadi MA, Azizi F: Validity and reliability of the Iranian version of the Pediatric Quality of Life Inventory ${ }^{\mathrm{m}} \mathbf{4} .0$ (PedsQL ${ }^{\mathrm{m}}$ ) Generic Core Scales in children. Health and quality of life outcomes 2012, 10:3.

36. Amiri P, Ardekani EM, Jalali-Farahani S, Hosseinpanah F, Varni JW, Ghofranipour F, Montazeri A, Azizi F: Reliability and validity of the Iranian version of the Pediatric Quality of Life Inventory ${ }^{\mathrm{TM}} 4.0 \mathrm{Generic}^{-}$ Core Scales in adolescents. Quality of Life Research 2010, 19:1501-1508.

37. Lovibond PF, Lovibond SH: The structure of negative emotional states: Comparison of the Depression Anxiety Stress Scales (DASS) with the Beck Depression and Anxiety Inventories. Behaviour research and therapy 1995, 33:335-343.

38. Asghari A, Saed F, Dibajnia P: Psychometric properties of the Depression Anxiety Stress Scales-21 (DASS-21) in a non-clinical Iranian sample. Int J psychol 2008, 2:82-102.

39. Lee S-Y, Song X-Y: Basic and advanced Bayesian structural equation modeling: With applications in the medical and behavioral sciences. John Wiley \& Sons; 2012.

40. Hooper D, Coughlan J, Mullen MR: Structural equation modelling: Guidelines for determining model fit. Electronic journal of business research methods 2008, 6:53-60.

41. Giannakopoulos G, Dimitrakaki C, Pedeli X, Kolaitis G, Rotsika V, Ravens-Sieberer U, Tountas Y: Adolescents' wellbeing and functioning: relationships with parents' subjective general physical and mental health. Health and Quality of Life Outcomes 2009, 7:100.

42. Wong ST: The relationship between parent emotion, parent behavior, and health status of young African American and Latino children. Journal of Pediatric Nursing 2006, 21:434-442. 
43. Baker CE: Maternal depression and the development of executive function and behavior problems in Head Start: Indirect effects through parenting. Infant mental health journal 2018, 39:134-144.

44. Mazaheri E, Ghasemzadeh A, Saadat M, Karami S, Pourshahriari M: The Relationship between Parent's Anxiety and their Children's Self-Efficacy in Primary Schools. Procedia-Social and Behavioral Sciences 2011, 29:257-260.

45. Benton PM, Skouteris $\mathrm{H}$, Hayden M: Does maternal psychopathology increase the risk of pre-schooler obesity? A systematic review. Appetite 2015, 87:259-282.

46. Duarte CS, Shen S, Wu P, Must A: Maternal depression and child BMI: longitudinal findings from a US sample. Pediatric obesity 2012, 7:124-133.

47. Cutting TM, Fisher JO, Grimm-Thomas K, Birch LL: Like mother, like daughter: familial patterns of overweight are mediated by mothers' dietary disinhibition-. The American journal of clinical nutrition 1999, 69:608-613.

48. Gustafson SL, Rhodes RE: Parental correlates of physical activity in children and early adolescents. Sports medicine 2006, 36:79-97.

49. Shaban LH, Vaccaro JA, Sukhram SD, Huffman FG: Do mothers affect daughter's behaviors? Diet, physical activity, and sedentary behaviors in Kuwaiti mother-daughter dyads. Ecology of food and nutrition 2018, 57:109-123.

50. Tsiros MD, Olds T, Buckley JD, Grimshaw P, Brennan L, Walkley J, Hills AP, Howe P, Coates AM: Healthrelated quality of life in obese children and adolescents. International journal of obesity 2009, 33:387.

51. Petersen S, Moodie M, Mavoa H, Waqa G, Goundar R, Swinburn B: Relationship between overweight and health-related quality of life in secondary school children in Fiji: results from a cross-sectional population-based study. International journal of obesity 2014, 38:539-546.

52. Von Rueden U, Gosch A, Rajmil L, Bisegger C, Ravens-Sieberer U: Socioeconomic determinants of health related quality of life in childhood and adolescence: results from a European study. Journal of Epidemiology \& Community Health 2006, 60:130-135.

53. Spurrier NJ, Sawyer MG, Clark JJ, Baghurst P: Socio-economic differentials in the health-related quality of life of Australian children: results of a national study. Australian and New Zealand Journal of Public Health 2003, 27:27-33.

54. Alipour A, Yaseri M, Maheri A, Garmaroudi GR: Health-Related Quality of Life of High School Students in Tehran, Iran. Journal of School of Public Health and Institute of Public Health Research 2017, 14:57-72.

55. Nomaguchi KM, Brown SL: Parental strains and rewards among mothers: The role of education. Journal of Marriage and Family 2011, 73:621-636.

56. Leinonen JA, Solantaus TS, Punamäki RL: Parental mental health and children's adjustment: The quality of marital interaction and parenting as mediating factors. Journal of child psychology and psychiatry 2003, 44:227-241. 
57. Waylen A, Stewart-Brown S: Factors influencing parenting in early childhood: a prospective longitudinal study focusing on change. Child: care, health and development 2010, 36:198-207.

58. Bøe T, Sivertsen B, Heiervang E, Goodman R, Lundervold AJ, Hysing M: Socioeconomic status and child mental health: The role of parental emotional well-being and parenting practices. Journal of abnormal child psychology 2014, 42:705-715.

59. Augustine JM, Crosnoe R: Mothers' depression and educational attainment and their children's academic trajectories. Journal of Health and Social Behavior 2010, 51:274-290.

60. Parkes A, Sweeting H, Wight D: Parenting stress and parent support among mothers with high and low education. Journal of Family Psychology 2015, 29:907.

61. Bolton K, Kremer P, Rossthorn N, Moodie M, Gibbs L, Waters E, Swinburn B, de Silva A: The effect of gender and age on the association between weight status and health-related quality of life in Australian adolescents. BMC Public Health 2014, 14:898.

62. Bisegger C, Cloetta B, von Bisegger U, Abel T, Ravens-Sieberer U: Health-related quality of life: gender differences in childhood and adolescence. Sozial-und Präventivmedizin 2005, 50:281-291.

63. Holder MK, Blaustein JD: Puberty and adolescence as a time of vulnerability to stressors that alter neurobehavioral processes. Frontiers in neuroendocrinology 2014, 35:89-110.

\section{Tables}

Table 1. Descriptive statistics of study participants 


$\begin{array}{llll}\text { Total } & \text { Boys } & \text { Girls } & \text { P value } \\ (n=231) & (n=118) & (n=113) & \end{array}$

\section{Children's characteristics}

\begin{tabular}{|c|c|c|c|c|}
\hline Age (years) & $13.8 \pm 3.1$ & $13.9 \pm 3.0$ & $13.8 \pm 3.2$ & 0.85 \\
\hline BMI z score & $0.74 \pm 1.5$ & $0.63 \pm 1.5$ & $0.86 \pm 1.4$ & 0.23 \\
\hline \multicolumn{5}{|l|}{ HRQoL (PedsQoL) } \\
\hline -Physical functioning & $89.6 \pm 11.3$ & $91.5 \pm 9.9$ & $87.6 \pm 12.3$ & 0.008 \\
\hline -Emotional functioning & $73.5 \pm 18.7$ & $77.1 \pm 15.7$ & $69.7 \pm 20.8$ & 0.003 \\
\hline -Social functioning & $89.1 \pm 13.0$ & $90.2 \pm 11.3$ & $88.0 \pm 14.5$ & 0.19 \\
\hline -School functioning & $83.7 \pm 14.5$ & $83.2 \pm 13.8$ & $84.2 \pm 15.3$ & 0.59 \\
\hline Total HRQoL & $84.7 \pm 11.3$ & $86.3 \pm 9.9$ & $83.0 \pm 12.4$ & 0.03 \\
\hline \multicolumn{5}{|l|}{ Maternal characteristics } \\
\hline Maternal age (years) & $42.2 \pm 5.8$ & $42.4 \pm 6.2$ & $41.9 \pm 5.3$ & 0.54 \\
\hline \multicolumn{5}{|c|}{ Maternal level of education n (\%) } \\
\hline -Primary & $36(15.6)$ & 21(17.8) & 15(13.3) & \multirow[t]{3}{*}{0.38} \\
\hline -Secondary & $132(57.1)$ & $69(58.5)$ & $63(55.8)$ & \\
\hline -Higher & $63(27.3)$ & $28(23.7)$ & $35(31.0)$ & \\
\hline \multicolumn{5}{|l|}{ Maternal job status n (\%) } \\
\hline -Housewife & $186(80.5)$ & $94(79.7)$ & $92(81.4)$ & \multirow[t]{2}{*}{0.86} \\
\hline -Working/student & $45(19.5)$ & $24(20.3)$ & 21(18.6) & \\
\hline \multicolumn{5}{|c|}{ Maternal emotional state (DASS-21) } \\
\hline -Depression & $4(0-10)$ & $4(0-10)$ & $4(0-10)$ & 0.89 \\
\hline -Anxiety & $6(2-12)$ & $6(2-14)$ & $6(2-12)$ & 0.97 \\
\hline -Stress & $14(8-20)$ & $16(8-20)$ & $14(6-22)$ & 0.38 \\
\hline
\end{tabular}


Table 2. Sex-specific associations between maternal characteristics and child's HRQoL

\begin{tabular}{|c|c|c|c|c|c|}
\hline \multirow[t]{2}{*}{ Predictor } & \multirow[t]{2}{*}{ Response } & \multicolumn{2}{|l|}{ Boys } & \multicolumn{2}{|l|}{ Girls } \\
\hline & & Estimate* & $95 \% \mathrm{Cl}$ & Estimate* & $95 \% \mathrm{Cl}$ \\
\hline Maternal age (years) & $\begin{array}{l}\text { Maternal emotional } \\
\text { state }\end{array}$ & -0.12 & $\begin{array}{l}(-0.26 \\
0.02)\end{array}$ & -0.12 & $\begin{array}{l}(-0.26 \\
0.02)\end{array}$ \\
\hline Maternal education & & -0.23 & $\begin{array}{l}(-0.37 \\
-0.07)\end{array}$ & -0.23 & $\begin{array}{l}(-0.37 \\
-0.07)\end{array}$ \\
\hline $\begin{array}{l}\text { Maternal working } \\
\text { status }\end{array}$ & & 0.01 & $\begin{array}{l}(-0.14 \\
0.15)\end{array}$ & 0.01 & $\begin{array}{l}(-0.14 \\
0.15)\end{array}$ \\
\hline Maternal age (years) & Child's BMI Z score & -0.10 & $\begin{array}{l}(-0.31 \\
0.13)\end{array}$ & -0.06 & $\begin{array}{l}(-0.33, \\
0.22)\end{array}$ \\
\hline Maternal education & & 0.10 & $\begin{array}{l}(-0.16 \\
0.36)\end{array}$ & 0.11 & $\begin{array}{l}(-0.17 \\
0.39)\end{array}$ \\
\hline $\begin{array}{l}\text { Maternal working } \\
\text { status }\end{array}$ & & -0.13 & $\begin{array}{l}(-0.37 \\
0.12)\end{array}$ & -0.21 & $\begin{array}{l}(-0.46, \\
0.07)\end{array}$ \\
\hline $\begin{array}{l}\text { Maternal emotional } \\
\text { state }\end{array}$ & & 0.12 & $\begin{array}{l}(-0.13 \\
0.37)\end{array}$ & 0.25 & $\begin{array}{l}(0.06 \\
0.53)\end{array}$ \\
\hline
\end{tabular}

\begin{tabular}{|c|c|c|c|c|c|}
\hline Child age (years) & Child's HRQoL & -0.21 & $\begin{array}{l}(-0.40 \\
-0.01)\end{array}$ & -0.33 & $\begin{array}{l}(-0.53, \\
-0.10)\end{array}$ \\
\hline Child BMI Z score & & 0.02 & $\begin{array}{l}(-0.25 \\
0.28)\end{array}$ & 0.21 & $\begin{array}{l}(-0.10, \\
0.51)\end{array}$ \\
\hline Maternal age (years) & & -0.12 & $\begin{array}{l}(-0.03 \\
0.06)\end{array}$ & 0.19 & $\begin{array}{l}(-0.05, \\
0.41)\end{array}$ \\
\hline Maternal education & & -0.24 & $\begin{array}{c}(-0.44, \\
-0.02)\end{array}$ & -0.14 & $\begin{array}{l}(-0.35 \\
0.08)\end{array}$ \\
\hline $\begin{array}{l}\text { Maternal working } \\
\text { status }\end{array}$ & & 0.05 & $\begin{array}{l}(-0.15 \\
0.24)\end{array}$ & 0.12 & $\begin{array}{l}(-0.10 \\
0.34)\end{array}$ \\
\hline $\begin{array}{l}\text { Maternal emotional } \\
\text { state }\end{array}$ & & -0.24 & $\begin{array}{l}(-0.44, \\
-0.04)\end{array}$ & -0.31 & $\begin{array}{l}(-0.54, \\
-0.08)\end{array}$ \\
\hline
\end{tabular}


*Standardized path coefficients and their $95 \%$ confidence intervals $(\mathrm{Cl})$

\section{Figures}

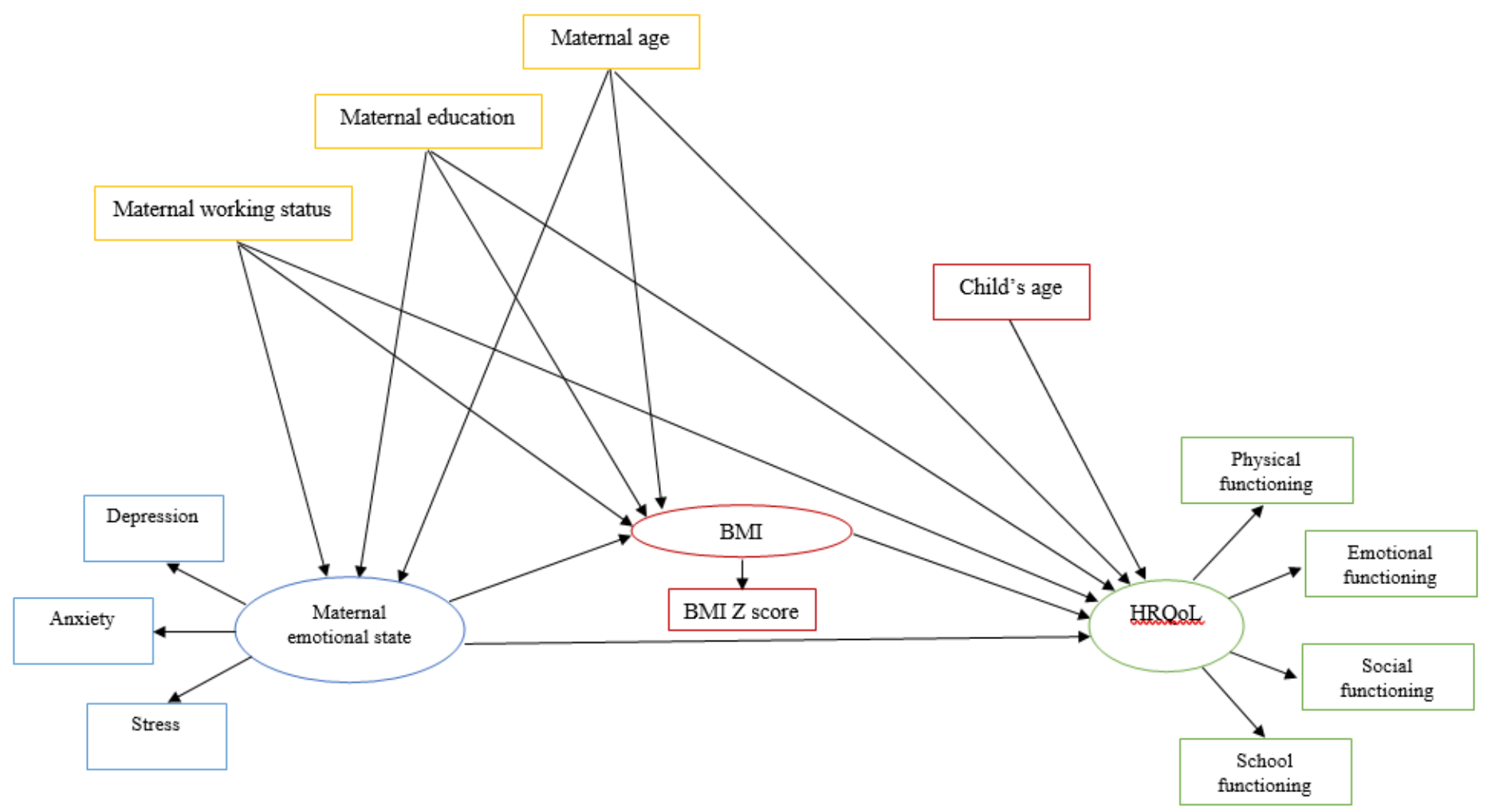

Figure 1

A conceptual model for the relation of maternal characteristics and emotional states with children's BMI Z- scores and health-related quality of life
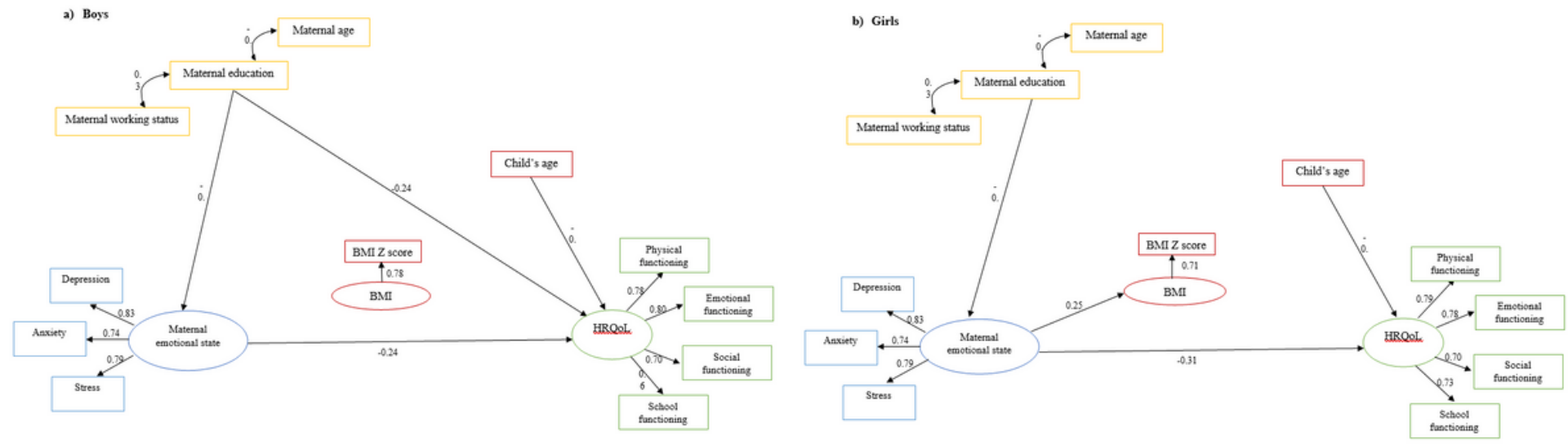

Figure 2 
Final structural models after testing the relation of maternal characteristics and emotional states with children's BMI Z- scores and health-related quality of life (a- men and b- women). Fit indices were acceptable for both SEM models in boys $(X 2=69.8, \mathrm{DF}=42, \mathrm{X} 2 / \mathrm{DF}=1.66, \mathrm{RMSEA}=0.75, \mathrm{GFI}=0.91, \mathrm{CFI}$ $=0.93, \mathrm{IFI}=0.93, \mathrm{NFI}=0.90)$ and girls $(\mathrm{X}=74.3, \mathrm{DF}=42, \mathrm{X} 2 / \mathrm{DF}=1.77, \mathrm{RSMEA}=0.80, \mathrm{GFI}=0.90, \mathrm{CFI}=$ $0.91, \mathrm{IFI}=0.92, \mathrm{NFI}=0.91$ ) 